\title{
The Road to Recovery: Building Physical and Emotional Trust when Engaging with Extension Clientele ${ }^{1}$
}

\author{
Colby Silvert, Cody Gusto, and John Diaz ${ }^{2}$
}

This second publication in the Road to Recovery series provides information and recommendations to engage safely in person or virtually and to address emotional and physical trust gaps clientele may experience in the face of a pandemic.

\section{Introduction}

Now is a crucial time for Extension professionals to engage with clientele. Buys (2020) claims cooperative Extension should play a key role, together with the public health sector, to provide people with information and services related to the coronavirus disease 2019 (COVID-19) outbreak. Moreover, many Extension professionals already have experience in emergency and disaster preparedness, response, and recovery that can be applied in the present context (Buys, 2020).

Extension clientele are facing a multitude of unprecedented challenges related to COVID-19. In the agriculture sector, both the current pandemic and the road to recovery are posing extreme vulnerability for producers and workers (Food and Agriculture Organization [FAO], 2020). Additionally, we are seeing high levels of agricultural market fluctuations, chronic/systematic labor shortages, and constrained access to services, including Extension (FAO, 2020). Urban communities (especially African Americans, Latinos, and other minorities) have also disproportionately suffered from COVID-19 (van Dorn, 2020). Where people live and work can be detrimental to their health. Racial and ethnic minorities commonly live in multigenerational, crowded conditions and work on the "front lines" of the labor market, unable to easily socially distance from the public (Marshall, 2020). Understanding these pressing issues should be prioritized by Extension professionals who are positioned to help address gaps in knowledge and services affecting both rural and urban communities.

Just as our engagement with others in daily life has transformed, we must rethink how we interact with and assist clientele to ensure their safety and our own. To do this, it is critical we understand that the pandemic has exacerbated emotional trauma and anxiety (Higgins, 2020). This publication therefore aims to build Extension professionals' sensitivity to the needs and emotional strains that COVID-19 presents for clients, as well as the strategies needed for effective recovery. The information and recommendations presented below are relevant to both in-person and virtual engagement.

\section{The Case for Building Trust}

Building trust requires intentional, strategic effort and can be hugely beneficial in our response and recovery to COVID-19. Research has demonstrated that communities with greater levels of trust react better to crises, have

1. This document is AEC713, one of a series of the Department of Agricultural Education and Communication, UF/IFAS Extension. Original publication date November 2020. Visit the EDIS website at https://edis.ifas.ufl.edu for the currently supported version of this publication.

2. Colby Silvert, graduate assistant; Cody Gusto, graduate student; and John Diaz, assistant professor and Extension specialist, Department of Agricultural Education and Communication; UF/IFAS Extension, Gainesville, FL 32611.

The Institute of Food and Agricultural Sciences (IFAS) is an Equal Opportunity Institution authorized to provide research, educational information and other services

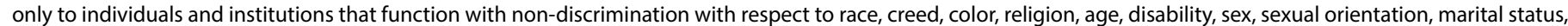

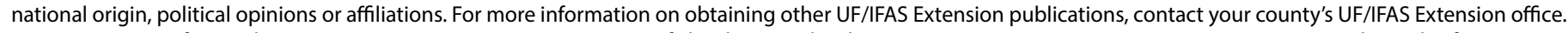
U.S. Department of Agriculture, UF/IFAS Extension Service, University of Florida, IFAS, Florida A \& M University Cooperative Extension Program, and Boards of County Commissioners Cooperating. Nick T. Place, dean for UF/IFAS Extension. 
improved health outcomes, and are more innovative (Helliwell et al., 2014; Knack, 2001; Newton, 2020). While we may think of trust during a pandemic as relating to physical well-being, trust also applies to emotional safety and needs. According to Lee et al. (2020), increasing trust with stakeholders is a current need but will also be critical for recovery and future resilience. The following sections define physical and emotional dimensions of trust and provide recommendations and examples that may be applied by Extension professionals.

\section{Physical Trust}

Physical trust is "trust that your physical space is safe" (Lee et al., 2020, p. 4). Physical trust is most essential when working with clients in the field or in person. In the first stages of planning any in-person engagement, you should review updated University of Florida (UF) Health (https:// coronavirus.ufhealth.org/), Centers for Disease Control (CDC) (https://www.cdc.gov/coronavirus/2019-ncov/index. html), and Florida Department of Health (https://floridahealthcovid19.gov/) guidelines. The following are examples of ways you can build physical trust with your clientele.

- Consider clients' access to technology, and when possible, offer virtual learning activities and meetings to decrease risks. However, to better ensure equity among clientele and reach vulnerable populations, be mindful that many households lack access to high-speed internet and technology (Puckett \& Rafalow, 2020). Hence, in-person interaction may be advisable.

- When you do need to engage in person, assess beforehand if clients will be able to trust that the environment will be safe from major COVID-19 risks. This could mean hosting a training outside with ample space and airflow. Additionally, you should check for data on local infection rates where you plan to visit or hold an event.

- On the day of a training or client visit, offer protective equipment such as masks and hand sanitizer.

- Use any opportunity to model and educate clients about COVID-19. Even if you are working with clientele on a different topic, by modeling preventative behaviors and sharing up-to-date information from relevant and trusted sources, you have the opportunity to spread important awareness.

\section{Emotional Trust}

Emotional trust is "trust that your emotional and societal needs are being safeguarded" (Lee et al., 2020, p. 4).

Building emotional trust may seem more difficult without understanding the emotional needs of your clients beforehand. Many of your clients, like all of us, have been overwhelmed by the magnitude and uncertainty of the COVID-19 outbreak (Higgins, 2020). The following steps can help you build comfort, awareness, and emotional trust with your clients in person or via virtual platforms.

- Many clients may not know where to turn for trusted information and thus feel helpless. Attempt to facilitate safe spaces in which your clients can ask questions and trust you will do your best to answer and/or connect them to sound information.

- Your clients may not feel comfortable speaking out in a public forum. When working with a group, provide an anonymous question or concern box, and always leave your contact information for them to follow up.

- Design your trainings and engagements to be sensitive and responsive to the social and structural dynamics affecting your clients. This is especially important at the household and family levels. For instance, many parents have taken on extra responsibilities (and emotional strains), such as caring for children involved in remote education. Educational experiences for many youth and children have also been altered dramatically. Identifying and trying to understand these issues is important to accommodate the daily lives of your clients and promote both well-being and resilience. Gillen (2012) also recommends Extension professionals encourage families to work together in times of crisis, even including children, to identify their needs and make decisions.

- While you likely are not a trained mental health professional and may not always be in a position to lead discussion on the negative mental health impacts of COVID-19, be open and empathetic when possible. Additionally, consider providing mental health resources and information (e.g., the CDC guidelines on coping with stress [https://www.cdc.gov/coronavirus/2019-ncov/ daily-life-coping/managing-stress-anxiety.html] and local resources).

- Work to collaborate and build support networks for your clients to reduce uncertainty and increase overall trust. In many previous cases, competing interests, such as health care actors, have worked together during the pandemic to track COVID-19 and provide relief services (Lee et al., 2020). The next article in this series contains more information on specific steps you can take to form support networks and boost community resilience. 


\section{Conclusion}

A foundation of physical and emotional trust is essential to engage impactfully and safely with clients in the field, in communities, and over virtual platforms. To build long-term trust, we should manage expectations around trust. Some clients may be apprehensive about trusting an Extension professional, especially in the current context. Hence, you may first be perceived as "the outsider," requiring efforts to earn the trust from your clients with time, multiple interactions, and improved rapport (Suvedi \& Kaplowitz, 2016). UF/IFAS Extension has compiled and produced additional resources and articles (including several in Spanish, Haitian Creole, and Mandarin), to support Extension professionals in addressing client needs related to the COVID-19 pandemic (https://edis.ifas.ufl. edu/topic_covid19).

\section{References}

Food and Agriculture Organization of the United Nations. (2020). Extension and advisory services: At the frontline of the response to COVID-19 to ensure food security. https:// www.agrilinks.org/sites/default/files/resources/fao_covid_and_eas_2020.pdf

Gillen, M. (2013). Coping with a money crunch: Family cooperation. FCS7005. Gainesville: University of Florida Institute of Food and Agricultural Sciences. https://edis.ifas. ufl.edu/fy 227

Helliwell, J. F., Huang, H., \& Wang, S. (2014). Social capital and well-being in times of crisis. Journal of Happiness Studies, 15(1), 145-162. 10.1007/s10902-013-9441-Z

Higgins, T. (2020, March 27). Coronavirus pandemic could inflict emotional trauma and PTSD on an unprecedented scale, scientists warn. CNBC. https://www.cnbc. com/2020/03/27/coronavirus-pandemic-could-inflict-longlasting-emotional-trauma-ptsd.html

Knack, S. (2001). Trust, associational life and economic performance. World Bank. https://mpra.ub.uni-muenchen. de/27247/1/MPRA_paper_27247.pdf

Lee, J., Sniderman, B., Marquard, B., Galletto, N., Geeanpersadh, P., \& Cherny, M. (2020). Embedding trust into COVID-19 recovery. Deloitte Insights. https://www2. deloitte.com/us/en/insights/economy/covid-19/buildingtrust-during-covid-19-recovery.html
Marshall, W. F. (2020). Coronavirus infection by race: What's behind the health disparities? Mayo Clinic. https:// www.mayoclinic.org/diseases-conditions/coronavirus/ expert-answers/coronavirus-infection-by-race/ faq-20488802

Newton, K., Stolle, D., \& Zmerli, S. (2018). Social and political trust. The Oxford handbook of social and political trust.

Puckett, C., \& Rafalow, M. (2020). COVID-19, technology, and implications for educational equity (sociology of education). ASA Footnotes. https://www.asanet.org/ news-events/footnotes/may-jun-2020/research-policy/ covid-19-technology-and-implications-educational-equitysociology-education

Suvedi, M., \& Kaplowitz, M. (2016). What every extension worker should know: Core competency handbook. Modernizing Extension and Advisory Services. https://meas.illinois. edu/wp-content/uploads/2015/04/MEAS-2016-ExtensionHandbook-Suvedi-Kaplowitz-2016_02_15.pdf

van Dorn, A., Cooney, R. E., \& Sabin, M. L. (2020). COVID-19 exacerbating inequalities in the US. Lancet, 395(10232), 1243-1244. https://dx.doi. org/10.1016\%2FS0140-6736(20)30893-X

\section{Appendix: The Road to Recovery Series Overview}

The COVID-19 pandemic created the need for this Road to Recovery series of EDIS publications. Six publications are included, covering topics to assist Extension professionals and State specialists in addressing client needs and evaluating techniques for virtual engagement. Brief summaries of each publication in the series are provided below.

\section{The Road to Recovery \# 1: Introduction}

Summarizes the implications of the COVID-19 pandemic on Extension professionals' operations and presents necessary adaptations and key considerations to safely improve delivery and impact.

\section{The Road to Recovery \#2: Building Physical and Emo- tional Trust When Engaging with Extension Clientele}

Provides information and recommendations to address emotional and physical trust gaps clientele may experience in the face of a pandemic by using intentional, strategic efforts when engaging in the field or via virtual platforms. 


\section{The Road to Recovery \#3: Facilitating Community Resilience for Effective Pandemic Response}

Considers challenges posed by the pandemic and the importance of community-led initiatives and provides alternative strategies for facilitating building resiliency, capacity, and social capital involving community stakeholders and clients.

\section{The Road to Recovery \#4: Evaluating Virtual Techniques to Reach Clientele and Promote Equity}

Offers guidance on how to effectively assess which audiences are being reached through virtual engagement and which audiences may be "falling through the cracks;" includes information on leveraging social media and virtual platform analytics, applying audience segmentation, and using online surveys and polls.

\section{The Road to Recovery \#5: Evaluating Virtual Facilitation to Build Trust}

Provides information on how educators can evaluate their efforts to facilitate trust through remote learning and virtual engagement, especially important during a pandemic; considers users' concerns about cybersecurity and common anxieties, discomfort, and competency gaps using online platforms.

\section{The Road to Recovery \#6: Evaluating Virtual Strategies to Build Community Capacity and Resiliency}

Offers support for agents interested in evaluating their use of virtual strategies to promote participatory engagement and community-capacity building; provides recommendations for agents to better assess whether virtual techniques improve users' perceptions of collective efficacy and community capacity during pandemic scenarios. 